\title{
Acellular Amniotic Membrane Patch Regeneration for Burn Injury: The Future for Wound Healing
}

\section{Tayná Dias' ${ }^{1}$ Kalyane Machadoํㅜ, Kátia Renata Antunes Kochla ${ }^{1}$, Ricardo Cunha1, Marco André Cardoso ${ }^{1}$, Rossana Baggio Simeoni' ${ }^{2,3}$, Vinicius Coneglian Santos ${ }^{1}$, Péricles Varella Gomes ${ }^{1,4}$, Luiz Claudio Sobrinho do Nascimento ${ }^{1}$, Maria Elisa Brum do Nascimento ${ }^{1}$, Luiz Cesar Guarita-Souza ${ }^{2}$, Alessandro Brawerman', Julio Cesar Francisco ${ }^{1}$}

${ }^{1}$ School of Health Sciences, Positivo University, Curitiba, Brazil; ${ }^{2}$ School of Medical Sciences, Pontifical Catholic University of Paraná, Curitiba, Brazil; ${ }^{3}$ The Paraná Institute of Technology, Curitiba, Brazil; ${ }^{4}$ Gel Lab, Michigan State University, East Lansing, USA

Correspondence to: Julio C. Francisco, julio.apfr@gmail.com

Keywords: Skin Regeneration, Amniotic Membrane, Wound Healing, Tissue Engineering

Received: June 24, $2019 \quad$ Accepted: August 18, $2019 \quad$ Published: August 21, 2019

Copyright $\odot 2019$ by author(s) and Scientific Research Publishing Inc.

This work is licensed under the Creative Commons Attribution International License (CC BY 4.0).

http://creativecommons.org/licenses/by/4.0/

\section{(c) (i) Open Access}

\section{ABSTRACT}

Acellular amniotic membrane (AAM) is a biodegradable and biocompatible natural that has a wide range of applications in the field of pharmaceutics, biomedical, chemical and cosmetics industry. One of the most interesting characteristics of AAM is its antibacterial and anti-inflammatory, anti-angiogenic, anti-fibrosis activity is an attractive approach for treating inflammatory disorders, wounds, and burns. The isolated use of AAM may not be sufficient to produce an adequate anti-inflammatory and antimicrobial effect to fulfill different purposes, has attracted considerable attention that has similar properties to the native tissues. This mini-review offers a focuses on modern aspects of the biomaterials, growth factors, biocompatibility, and acellular matrix which are the basic elements for use in the tissue regeneration and replacement after an injury.

\section{INTRODUCTION}

The incidence of people with burns has been an increase progressively over the last decades, and it is estimated that more than one 1.2 million people die each year from burn in the USA [1]. Approximately 1 million people are diagnosed with burns per year, and 100.000 patients sought inpatient and, of these, about 2.500 patients will die directly or indirectly as a result of his burns in Brazil [2].

Recent advances in biotechnology have shown that use acellular patch has an important role in regenerate tissues, demonstrating exert various health benefits. Acellular patch fosters a broad spectrum in the 
field of regenerative medicine applications due to their biocompatibility and biofunctionality being tested in humans for dermal and reconstructive surgery applications [3].

The acellular amniotic membrane (AAM) a new strategy for tissue regeneration, due to its good biocompatibility and biodegradability and the majority are discarded with the placenta after parturiency [4].

This mini-review focuses on modern aspects of the biomaterials, growth factors, biocompatibility, and acellular matrix are the basic elements for use in the tissue regeneration and replacement after an injury.

\section{SKIN NORMAL ANATOMY}

In normal anatomy, the skin is composed of the epidermis, the dermis, the hypodermis, and its annexes. The epidermis is composed of an outer layer, being the first layer consisting of keratinocytes, which contains several proteins, constituting a barrier between the environment and the internal organs and tissues. The middle layer, the dermis, is composed essentially of the fibrillar structural protein known as collagen. The dermis or corium formed by collagen containing a complex microcirculation of arterioles, venules, and capillaries [5].

\section{BURN INJURY}

Burns are injuries caused by fire, overheated materials, electricity, contact with chemical and radioactive substances, with exposure of this material to the body, can cause partial or total damage in the skin tissues and its annexes [6]. In the face of injuries caused by burns, the patient meets with numerous sequels could result in physical and psychological limitations, changing the quality of life in daily activities and even social relationships [7].

The burn patient has a long duration of hospitalization, thus nurses have a responsibility to answer questions and inform the patient, to exercise their autonomy in making decisions about the care of your health. The nurse must also defend patients' rights and ensure the quality of care [8].

\section{MEMBRANE AMNIOTIC (AM)}

Due to burning injuries and impacts on public health due to the great economic consumption for treatment, constant research to improve the prognosis and the cost of treatment [9].

With innovations on the extra-embryonic stem cells that are derived from the corium and the amniotic membrane has been extensively skin engineering studies in recent years. The amniotic membrane that is material in this study is considered multipotent and has a high proliferation rate, good plasticity and lack of immune response [10].

Human amniotic membrane is composed of 5 layers containing various types of cells, but the three are basal, mesenchymal and epithelial and basal layer critical to the healing process because it is rich in type IV collagen and laminin, cell-signaling proteins (cytokines), and growth factors which are important components during the inflammatory process the wound. The epithelial layer is basically composed of cuboidal epithelium that supports the membrane and the mesenchymal layer which is composed of connective tissue and is not vascularized [11].

The epithelial layer of the membrane does not have a range of surface antigens causing this material is less when grafting rejection, and contain a large number of growth factors so that there is not only a low rejection rate as facilitating epithelization. For being rich collagen in the basement membrane, the HAM has apoptosis of epithelial cells, decreasing the formation of tissue fibrosis [12].

\section{ACELLULAR MEMBRANE AMNIOTIC (AM)}

Decellularization processes have been used for various types of tissue in laboratory investigations and applications in regenerative medicine.

The removal of cells from a tissue, or decellularization, enables obtaining an extracellular matrix (ECM) 
residual. It can then be used as a structure for recellularization. The decellularization process may involve physical and chemical methods such as deformation, pressurization, agitation, sonication or freezing-defrosting cycles; chemical methods such as acid, base, alcohol or exposure to detergents, chelation treatments or use of osmotic stress; or enzymatic methods [3-11].

The most important part of the decellularization process of the tissue is to minimize the possibility of an adverse risk of immune rejection of cells and disease transmission, simultaneously preserving the underlying ECM structure [12].

Acellular amniotic membrane (AM) patch has been used in various surgeries, because it contains essential proangiogenic growth factors, including fibroblast growth factor-2 (FGF-2) and vascular endothelial growth factor (VEGF) that also promote endogenous mechanisms of repair and regeneration, such as angiogenesis or vasculogenesis [4-18].

AM has a surface compatible for cell attachment and proliferation, as well as for the new vessels formation within regenerating tissue.

\section{ANTI-INFLAMMATORY POTENTIAL AMNIOTIC MEMBRANE (AM)}

Inflammation is an important component during wound healing as part of the first phase of wound healing cascade, however, this early stage can harm the rest of the healing because it can change the regeneration processes related to tissue in cases such as the implantation of biomaterials or chronic wounds [13].

The inflammation is not only a result of the original injury; the surgical implant and the presence of biomaterials may also stimulate inflammation by foreign body reaction, so the biomaterial of human amniotic membrane is widely used; since this has no cell differentiation and promotes the development of collagen during re-epithelization of the lesion, causing the fibrous caps to fit over the aligned original epithelium compared to other materials [14].

The basement membrane AM promotes differentiation and migration of epithelial cells and also enhances the adhesion of basal epithelial cells. It also produces various growth factors such as fibroblast growth factor and transforming growth factor, which promotes epithelialization [15].

Another advantage of AM fundamental for use in tissue engineering are its anti-inflammatory, anti-bacterial, antis-caring, immunomodulatory, anti-angiogenic, anti-fibrotic, hemocompatibility and low immunogenicity property [15-18].

\section{CLINICAL USES OF AMNIOTIC MEMBRANE IN WOUNDS}

The human amniotic membrane has been used as biomaterials in the treatment of ocular surgery of wounds, burns, transplants and reconstructive surgery, due to its low cost and is used for different functions [15]. On Bioengineering Research involving this biomaterial has a collection that is constantly fed into the new discoveries of uses and forms of the same [16].

The most common use of this material is in the retina reconstructive surgery; osteogenesis, recovery of eye burns and ulcers, since they are a more complex healing process and with high chances of infection during the procedure. The goal of treatment of wounds resulting from burns are, remove devitalized tissue and cover the wound, in which there is a great risk of colonized open lesions can cause sepsis [17].

Due to the ability of bacterial resistance of the membrane, it is indicated for use in severe burn wounds since the proliferation of bacteria in the fabric it was low in the studies. The use of antibiotic-associated membrane decellularized has proved more effective in the healing process than the use of a fresh membrane [18].

\section{FINAL CONCLUSION AND FUTURE PERSPECTIVES}

The amniotic membrane is being used widely in several areas of medicine, with a recent increase in its indications and techniques in tissue regeneration. In short, the main challenges are the development of 
bioactive acellular patch or advanced strategies that promote the native and functional architecture and establish a structurally and physiologically interface is similar to the skin with focus on regenerative medicine. Considering the excellent role of using materials of natural origin in tissue regeneration, a large part of future studies is expected to focus on the deployment of acellular biomaterials path wound healing and tissue regeneration

\section{CONFLICTS OF INTEREST}

None declared.

\section{REFERENCES}

1. Rahman, M.S., et al. (2019) Characterization of Burn Wound Healing Gel Prepared from Human Amniotic Membrane and Aloe Vera Extract. BMC Complementary and Alternative Medicine, 19, 115. https://doi.org/10.1186/s12906-019-2525-5

2. Citron, I., et al. (2018) Assessing Burn Care in Brazil: An Epidemiologic, Cross-Sectional, Nationwide Study. Surgery, 163, 1165-1172. https://doi.org/10.1016/j.surg.2017.11.023

3. Pattar, S.S., FatehiHassanabad, A. and Fedak, P.W.M. (2019) Acellular Extracellular Matrix Bioscaffolds for Cardiac Repair and Regeneration. Frontiers in Cell and Developmental Biology, 7, 63.

https://doi.org/10.3389/fcell.2019.00063

4. Xue, S.L., Liu, K., Parolini, O., Wang, Y., Deng, L. and Huang, Y.-C. (2018) Human Acellular Amniotic Membrane Implantation for Lower Third Nasal Reconstruction: A Promising Therapy to Promote Wound Healing. Burns Trauma, 6, 34. https://doi.org/10.1186/s41038-018-0136-x

5. Francis, E., Kearney, L. and Clover, J. (2019) The Effects of Stem Cells on Burn Wounds: A Review. International Journal of Burns and Trauma, 9, 1-12.

6. Hu, Z., Yang, P., Zhou, C.X., Li, S.D. and Hong, P.Z. (2017) Marine Collagen Peptides from the Skin of Nile Tilapia (Oreochromis niloticus): Characterization and Wound Healing Evaluation. Marine Drugs, 15, 102. https://doi.org/10.3390/md15040102

7. Ahuja, R.B., Mulay, A.M. and Ahuja, A. (2016) Assessment of Quality of Life (QoL) of Burn Patients in India Using BSHS-RBA Scale. Burns, 42, 639-647.

8. Branski, L.K., Herndon, D.N., Celis, M.M., Norbury, W.B., Masters, O.E. and Jeschke, M.G. (2008) Amnion in the Treatment of Pediatric Partial-Thickness Facial Burns. Burns, 34, 393-399.

9. Harish, V., Tiwari, N., Fisher, O.M., Li, Z. and Maitz, P.K.M. (2019) First Aid Improves Clinical Outcomes in Burn Injuries: Evidence from a Cohort Study of 4918 Patients. Burns, 45, 433-439. https://doi.org/10.1016/j.burns.2018.09.024

10. Litwiniuk, M. and Grzela, T. (2014) Amniotic Membrane: New Concepts for an Old Dressing. Wound Repair and Regeneration, 22, 451-456. https://doi.org/10.1111/wrr.12188

11. John, S., Kesting, M.R., Paulitschke, P., Stöckelhuber, M. and von Bomhard, A. (2019) Development of a Tissue-Engineered Skin Substitute on a Base of Human Amniotic Membrane. Journal of Tissue Engineering, 10, Article ID: 2041731418825378.

12. Wilshaw, S.P., Kearney, J., Fisher, J. and Ingham, E. (2008) Biocompatibility and Potential of Acellular Human Amniotic Membrane to Support the Attachment and Proliferation of Allogeneic Cells. Tissue Engineering Part $A, 14,463-472$. https://doi.org/10.1089/tea.2007.0145

13. Joao De Masi, E.C., et al. (2016) The Influence of Growth Factors on Skin Wound Healing in Rats. Brazilian Journal of Otorhinolaryngology, 82, 512-521. https://doi.org/10.1016/j.bjorl.2015.09.011

14. Parani, M., Lokhande, G., Singh, A. and Gaharwar, A.K. (2016) Engineered Nanomaterials for Infection Control 
and Healing Acute and Chronic Wounds. ACS Applied Materials \& Interfaces, 8, 10049-10069. https://doi.org/10.1021/acsami.6b00291

15. Le, Q. and Deng, S.X. (2019) The Application of Human Amniotic Membrane in the Surgical Management of Limbal Stem Cell Deficiency. The Ocular Surface, 17, 221-229. https://doi.org/10.1016/j.jtos.2019.01.003

16. Cui, H., Chai, Y. and Yu, Y. (2019) Progress in Developing Decellularized Bioscaffolds for Enhancing Skin Construction. Journal of Biomedical Materials Research Part A, 107, 1849-1859. https://doi.org/10.1002/jbm.a.36688

17. Miller, D.D., Hasan, S.A., Simmons, N.L. and Stewart, M.W. (2019) Recurrent Corneal Erosion: A Comprehensive Review. Clinical Ophthalmology, 13, 325-335. https://doi.org/10.2147/OPTH.S157430

18. Kogan, S., Sood, A. and Granick, M.S. (2018) Amniotic Membrane Adjuncts and Clinical Applications in Wound Healing: A Review of the Literature. Wounds, 30, 168-173. 